\title{
Evaluation of Land Cover Change and Vegetation Dynamics Using Remote Sensing and DPSIR Framework in Kebbi State, Nigeria
}

\author{
Muhammad Mansur Aliero, $^{\text {ab }}$ Mohd Hasmadi Ismail $^{\mathrm{a}}$, Mohamad Azani Alias ${ }^{\mathrm{a}}$ and Alias \\ Mohd Sood $^{\mathrm{a}}$ \\ ${ }^{a}$ Universiti Putra Malaysia, 43400 Serdang, Selangor, Malaysia. \\ ${ }^{b}$ Kebbi State University $f$ Science and Technology, Aliero. Nigeria. \\ Corresponding Author: mansuraliero@yahoo.com
}

\begin{abstract}
Assessment of the trends of land cover and vegetation dynamics (VD) using remote sensing (RS) and indicators such as anthropogenic activities and the socio-demographic information is essential in order to make proper planning for sustainable management. This paper attempts to evaluate land cover change (LCC) and VD in Kebbi State, Nigeria using historical Landsat data from 1986-2016 by means of remote sensing. The Driver-Pressure-State-Impact-Response (DPSIR) framework was later employed using both primary and secondary data for a better understanding of the drivers, the state of the environmental condition, the causes as well as the impact of the change. The images were classified into five thematic land cover classes as Dense Vegetation, shrubs/built area, farmland, bare/grassland and water body by means of Maximum likelihood supervised classification technique in accordance with Anderson classification scheme level 1, with acceptable accuracy. Pre-classification and post-classification change detection (CD) methodologies were executed using Normalized difference vegetation index (NDVI) and Image differencing respectively. The study illustrates a steady decline in dense vegetation and shrubs/build areas while farmland and bare/grassland increases, however, water bodies remain unchanged. The DPSIR pin-point that the major drivers of change in the study area have been the pressing need for farming land as the population grows and socioeconomic demands including fuelwood consumption and endemic poverty. Expansion of Farming land, fuelwood consumption and the need for construction materials are identified as the main key elements exerting pressure for the change. The state of the condition indicates a steady decline in dense vegetation and shrubs areas while farmland and bare/grassland are increasing significantly. The impacts include land degradation, the decline in the provision ecosystem goods and services, biodiversity loss through loss of habitats. The study, however, noted that many international and national policies in response to land degradation are channelled toward land restoration and remediating of the environment, through afforestation programs and improving the livelihood of the rural people through providing alternative income sources since they depend heavily on land for sustenance. However, the state governments, communities and individual commonly organized annual tree planting campaign with the main purpose of environmental protection.
\end{abstract}

Keywords: Land cover change; vegetation dynamics; remote sensing; DPSIR; Kebbi state. 


\subsection{Introduction}

Ecosystem is a natural capital that assures not only a steady and constant supply of goods and services that are useful to populaces [1] but also plays an essential role in the global carbon cycle [2]; however, are in a state of permanent flux at various strategic spatial and temporal scales. The bases of these changes can be natural as well as anthropogenic or may be a combination of the two [3]. Natural disturbance events such as wildfire, insect and disease outbreaks, windstorms, hurricanes, floods, and droughts are generally expected to increase in frequency and magnitude, which will have major consequences for ecosystem dynamics [4]. Human-induced changes related to deforestation, unsustainable land use, overgrazing, illegal bush burning, fuelwood extraction are believed to have caused significant adverse changes in the ecosystem. subsequently, leads to its degradation. Monitoring the trends to which ecosystem is changing by the use of indicators such as land cover and socio-demographic information will be essential in order to make proper planning for sustainable ecosystem management. Nowadays, the advancement of geospatial technology such as RS and geographic information system (GIS) present the best efficient tool for analyzing land cover trends as demonstrated by many researchers $[5,6,7,8]$. Geospatial technologies in addition to conventional inventories can facilitate quantitative evaluation and provide a baseline for monitoring the extent, impacts and trend of LCC. This paper attempts to evaluate LCC and VD in Kebbi State, Nigeria using Landsat thematic mapper (TM), Enhanced thematic mapper (ETM) and operational land imager (OLI) imagery from 1986-2016 by means of RS technique. The DPSIR framework was employed using both primary and secondary data set for a better understanding of the drivers, the state of the environmental condition and the causes as well as the impact of the change with a view to addressing the issue in a sustainable manner. This research being the first to be conducted in the study area has the novelty of integrating RS data and conventional data for better understanding of phenomena under study. 


\subsection{Material and Method}

\subsection{The study area}

Table 1: Descriptive summary of the Study Area

\section{Description}

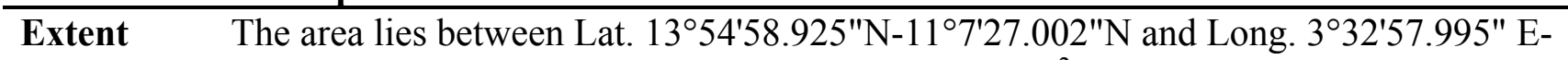
$4^{\circ} 53^{\prime} 19.708^{\prime \prime E}$, with the extent of about $20,657.5 \mathrm{Km}^{2}$, in the extreme North-western part of Nigeria (Fig. 1).

Climate The mean annual temperature lies between $35^{\circ} \mathrm{C}$ to $40^{\circ} \mathrm{C}$, average annual rainfall of about 850 inch and relative humidity ranges from $51-79 \%$ and $10-25 \%$ during rainy and dry seasons respectively.

Vegetation The vegetation is sudan savannah type and the soil is semi-arid type, characterized by frequent weathering and leaching due to poor soil structure and low organic matter content.

Economic The main economic activity is agriculture. Over (70\%) of the people practice one Activity form of agriculture or the other.

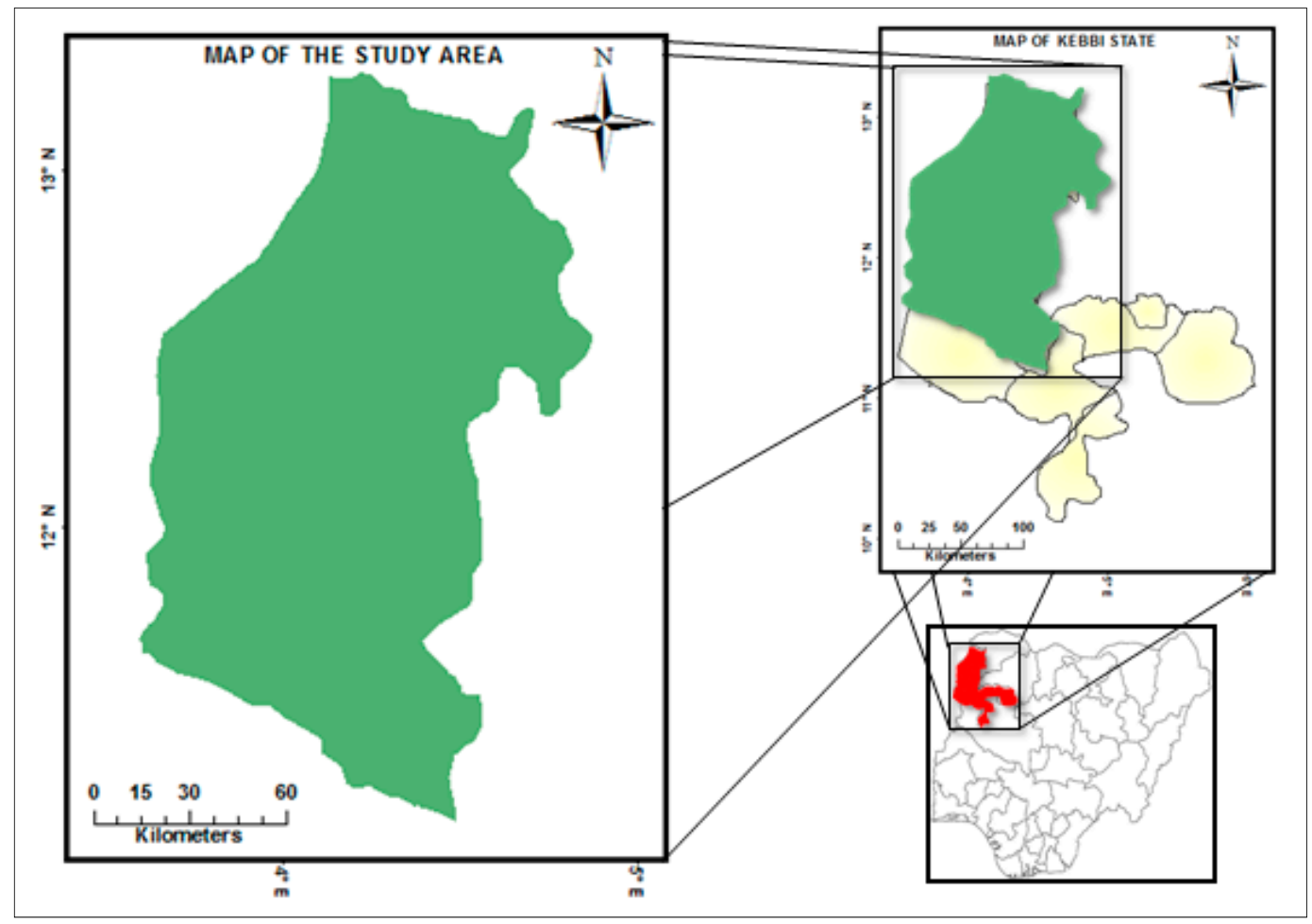

Fig. 1: Map of the study area from Nigerian Map 


\subsection{Data collection procedure}

Satellite (Landsat) images of 1986, 1996, 2006 and 2016 were acquired, Path and row 191/51 and 191/52 were downloaded from United States Geological Survey (USGS) website. Anniversary data acquisition dates were maintained in order to avoid biases that are due to the seasonality, this is essential for CD analysis. Field and other secondary data were collected mainly to determine the human influences on LCC and VD. Simple random sampling survey technique was conducted by means of focus group discussion and interview with the respondent using a structured questionnaire. Five (5) respondents were selected from six (6) villages each in the thirteen (13) provinces in the state. A total of three hundred and ninety (390) respondents/data were collected from the study area. The secondary data (population density, growth rate and other socio-economic variables) was collected from various existing literature and government agencies such as National Population Commission of Nigeria and Bureau of National Statistics of Nigeria websites.

\subsection{Data Analysis}

The whole process of RS data analysis is illustrated in Fig. 2. The analysis of remotely sensed data involves three processing steps; the first step is the preprocessing which includes image enhancement, radiometric calibration, ETM Gap fill and image rectification mainly carried out so as to standardize the imagery prepared for processing. Secondly, processing which involves classification of the imagery into thematic classes of land cover. Supervised maximum likelihood classifiers were adopted using ENVI 5.1 software. The whole image was classified into five thematic land cover classes as dense vegetation, shrubs/built area, farmland, bare/grassland and water body in accordance with Anderson classification scheme level 1. Thirdly, Post processing which includes classification accuracy assessment and CD. For the purpose of accuracy assessment, the area was mapped (ground truth) using a random sampling technique. A total of 156 sampled points across the entire study area was mapped and information on the land cover type, geographic information (longitude and latitude) was recorded and not less than 100 points was later used as ground truth regions for accuracy assessment. The confusion matrix of accuracy assessment indicates errors of omission and commission on the general classification accuracy and the Kappa coefficient in form of percentage. The percentage pinpoints the accuracy of the classification in relation to the reference data. Two broad methods of CD techniques are 
pre-classification and post-classification methods. The pre-classification method used the data values or digital number (DN) to analyses the change in land cover without classifying the image. The most widely used pre-classification method is spectral vegetation indices (SVI). These are commonly applied depending on the type of study i.e. NDVI is commonly used for vegetation studies and Normalized difference water index (NDWI) for water studies. On the other hand, post classification methods analyze the change after details classification of land cover. Examples include Image differencing, Image rationing, Image regression etc. For this study, the pre-classification CD using spectral vegetation indices (SVIs) was computed not only because of its relationship with the Net primary productivity (NPP) of the land but also an accurate classification method especially for Phenology/Vegetation studies using remotely sensed data [9]. NDVI was computed using (Equation 1) with Red and Near Infrared bands of Landsat (TM, ETM \& OLI). Post-classification CD was executed by using simple image differencing method because it is a most widely used technique for CD and has been used in a variety of geographical environments [10].

Landsat TM and ETM Band4 (NIR) and Band3 (Red) measures the reflectance at (0.63-0.69 um) (0.76-0.90 um) region of electromagnetic spectrum (EMR) respectively while Landsat (OLI) Band5 (NIR) and Band4 (Red) measures the reflectance at (0.636-0.673 um) (0.851-0.879 um) region of electromagnetic spectrum respectively.

The field data and these data from government agencies were analyzed by means of descriptive statistics using Statistical Package for the Social Sciences Version 22.

Table 2: NIR and Red bands for TM, ETM and OLI Source: (USGS website)

\begin{tabular}{lccc}
\hline \multicolumn{2}{c}{ Landsat OLI } & \multicolumn{2}{c}{ Landsat TM \& ETM } \\
Spectral Bands & Spectral Wavelength & Spectral Wavelength & Spectral Bands \\
Band 4-Red & $0.630 \mathrm{um}$ & $0.63 \mathrm{um}$ & Band 3-Red \\
Band 5-Near-Infrared & $0.845 \mathrm{um}$ & $0.76 \mathrm{um}$ & Band 4- Near Infrared \\
\hline
\end{tabular}

$$
\text { NDVI }=\frac{\text { NIR-Red }}{\text { NIR+Red }}
$$

Where: $N I R=$ Near-Infrared Band \& Red $=$ Red Band 


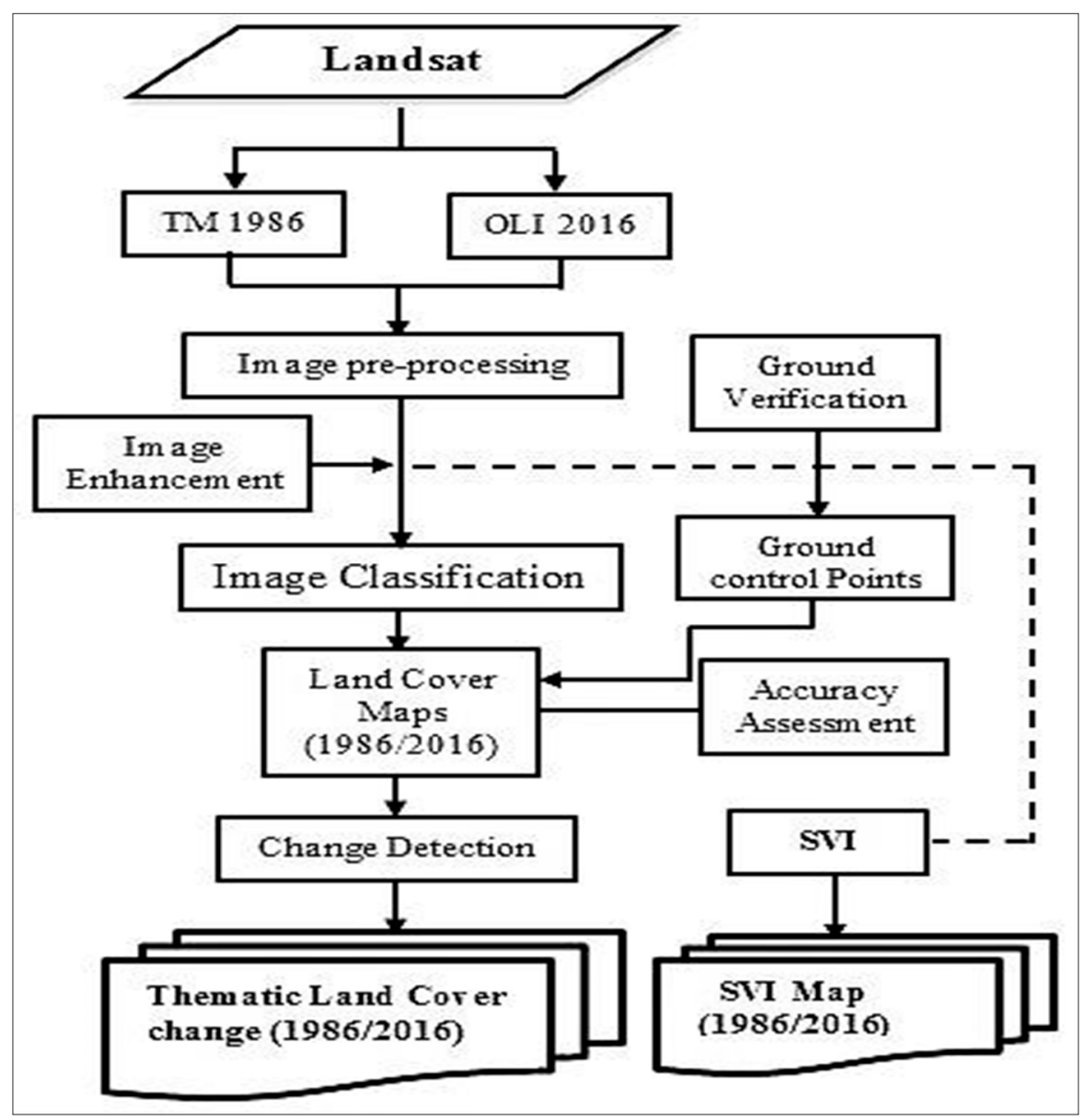

Fig. 2. Methodology flow-chart for remote sensing Data processing

\subsection{Driver-Pressure-State-Impact-Response (DPSIR) Framework}

The DPSIR framework was developed in 1994 by the Organization for Economic Co-operation and Development (OECD) and has since been renown widely by many scholars in many research discipline $[11,12,13,14,15,16,17]$; and many others for its advantages and suitability and also applicable to all kind of environmental problem [18]. DPSIR framework help in the understanding of the interrelating factors that alter the environment and as such offer not only a means to address the drivers and the state of the condition, but also the causes and the impact posed to the environment. 


\section{The DPSIR Framework}

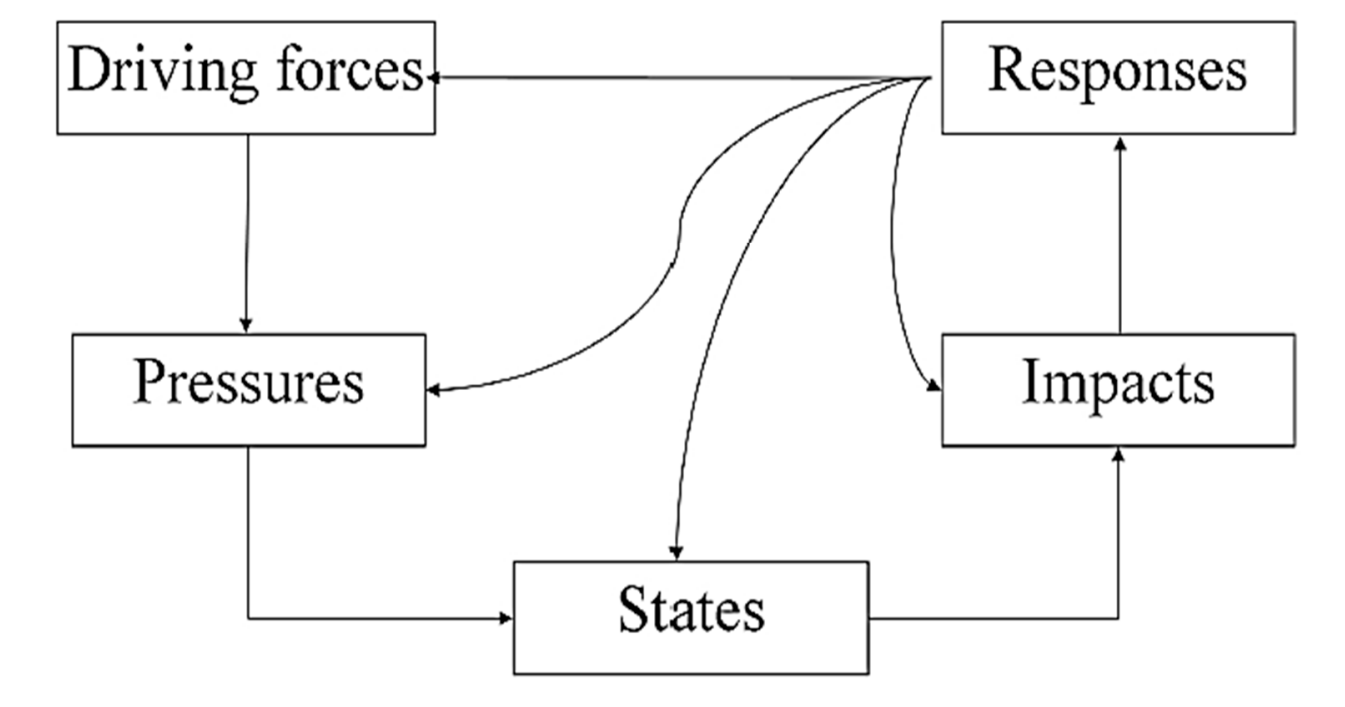

Fig. 3. The DPSIR Framework

\subsection{Result and Discussion}

\subsection{Analysis of Land cover}

The study area has a total land area of about $20,658 \mathrm{Km}^{2}$; in the year 1986 the whole area was covered by Dense Vegetation, Shrubs/ built area, Farmland, Bare/ grassland and Water body with each land cover amounting to $2,239 \mathrm{Km}^{2}$ (10.8\%), 8,907 $\mathrm{Km}^{2}(43.1 \%), 5,148 \mathrm{Km}^{2}$ (24.9\%), 4,2994 $\mathrm{Km}^{2}(20.8 \%)$ and $64.17 \mathrm{Km}^{2}(0.3 \%)$ respectively (Fig. 8a). Fig. 8(d) illustrate the distribution of the 2016 land area coverage, indicating that Dense Vegetation covering a land area of $869.15 \mathrm{Km}^{2}(4.2 \%)$, shrubs/built area account for the land area of $6,614.5 \mathrm{Km}^{2}(32.0 \%)$, while Farmland has a land area of $8,024.5 \mathrm{Km}^{2}(38.9 \%)$. Bare/grassland and water body have each a land area of 5,081.6 $\mathrm{Km}^{2}(24.6 \%)$ and $63.7 \mathrm{Km}^{2}(0.3 \%)$ respectively

\subsection{Change Detection}

The 1986 thematic land cover of the study area shows the largest areas was shrub/built area followed by farmland and bare/grassland. The lowest is dense vegetation and water body; 
however, in 2016, there was not a very significant change in all the classes except for the class 'dense vegetation' with a drastic decrease in the area.

The percentage land area occupied by shrubs/built area in 1986 was about $43.1 \%$ and has substantially lessened to $32.0 \%$ in 2016 . Likewise, farmland was $24.9 \%$ in 1986 when compared in 2016 it has increased to 38.9\%. Bare/grassland showed a slight increase from $20.8 \%$ in 1986 to $24.6 \%$ in 2016 . Dense vegetation, which used to be $10.8 \%$ in 1986 has drastically relegated and cascade down to $4.2 \%$ in 2016 . There is not a significant change in a water body as it maintained an area of $0.3 \%$ in both 1986 and 2016 themes.

Fig. 4 shows the thematic Map of classification analysis which indicates visually the changes that occur in the area from 1986-2016 (30 years). In three (3) decades, Dense Vegetation has declined rapidly by about $61 \%$ with its larger percentage being converted to bare/grassland and farmland. It is clear that there is a downturn in the shrubs Land by about $25.7 \%$ in the area. This is mainly attributed to the demand for firewood for domestic use and timber for construction purposes and this facilitated highly by cutting of trees in the forest leading to deforestation thereby remaining only the lower shrubs and other tree remnants to thrive in the area. Within this timeframe (1986-2016) Farmland has increased by 35.9\%, this is not surprising since there is pressure imposed by the demand for food as the population increased. Fig. 9 shows how the population density is increasing very rapidly. There are no doubt food supply increases but at the expense of losing forest, biodiversity and habitats for wildlife. Bare/grassland also increased by about $18.2 \%$ in the area, this is attributed to fact that most of the shrubs Land are been cutdown mainly to be used as fuelwood, burnt while clearing the land for farming or being grazed by animals. Furthermore, a linear trend line was constructed for each thematic class; time (years) was used as an independent variable ( $\mathrm{x}$ ) while thematic classes were used as a dependent variable (y) (Fig. 5). The trends illustrate a steady decline in dense vegetation and shrubs/build areas while farmland and bare/grassland increases.

\subsection{Analyses of Normalized Difference Vegetation Index (NDVI)}

The NDVI value varies from " +1 to -1 ". The values that are close to ' +1 ' indicate high vegetation while values close to ' 0 ' indicate less vegetation. ' 0 ' means no vegetation while ' -1 ' indicates other land cover types. Landsat TM and ETM sensors have Band 4 as NIR and Band 3 as RED while OLI sensor has Band 5 as NIR and Band 4 as the RED band as shown in table 2. 


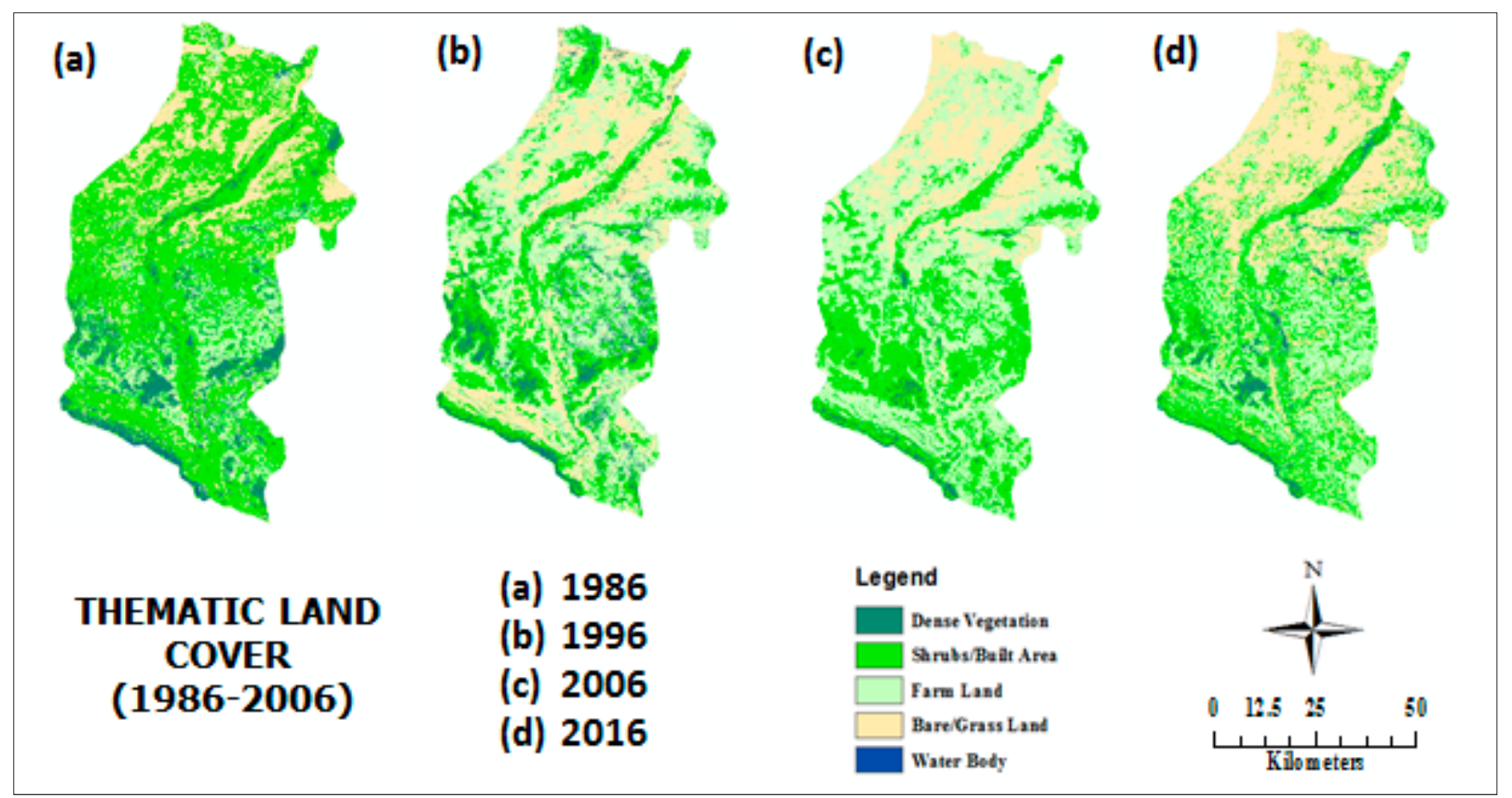

Fig. 4. Land cover Maps of the Study Area (1986-2016)

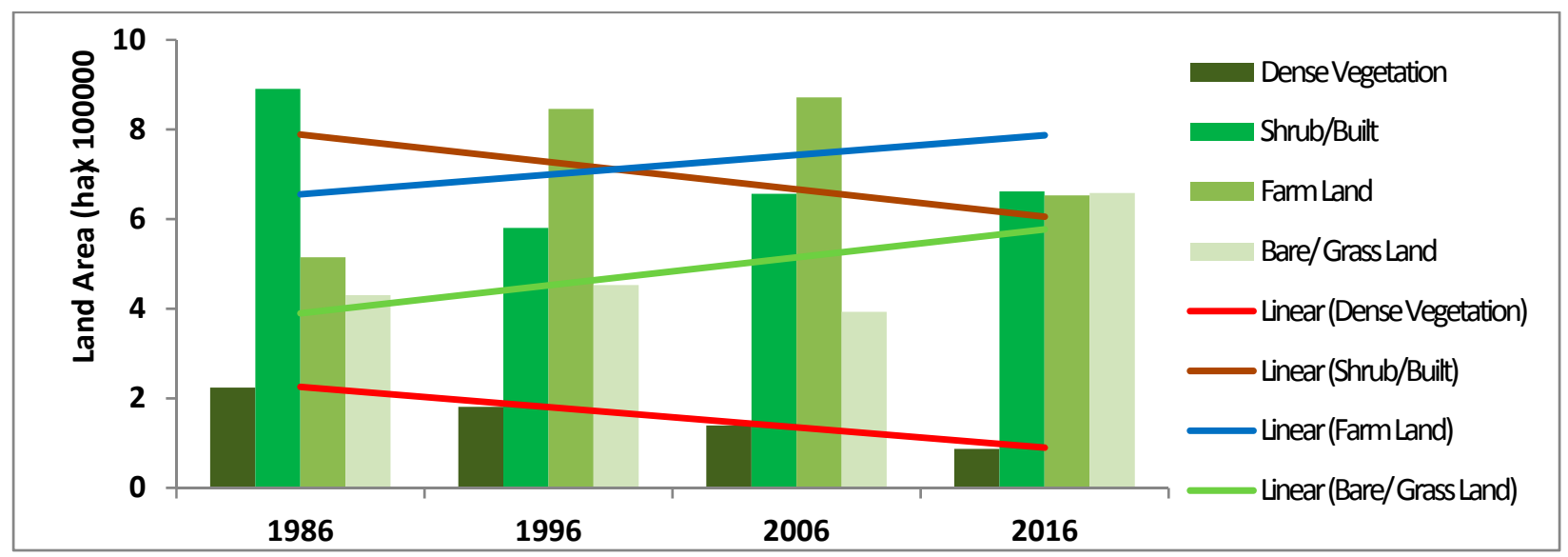

Fig. 5. Change in Vegetation Cover in the study area

The result of NDVI themes and classified NDVI (Fig. 6); However, Unsupervised classification by means of ISDATA classifiers were used to classify the NDVI result. Values close to ' +1 ' are classified as dense vegetation and values close to '0' are classified as Shrubs and less vegetation including dead grasses. Negative values including ' 0 ' are classified as No vegetation including built up and water body. To analyze further, a linear trend line was constructed for each NDVI class; time was used as an independent variable (x) while thematic classes were used as a dependent variable (y) (Fig. 7). The trend shows a decrease in dense vegetation and an increase in shrubs and less vegetation class. 


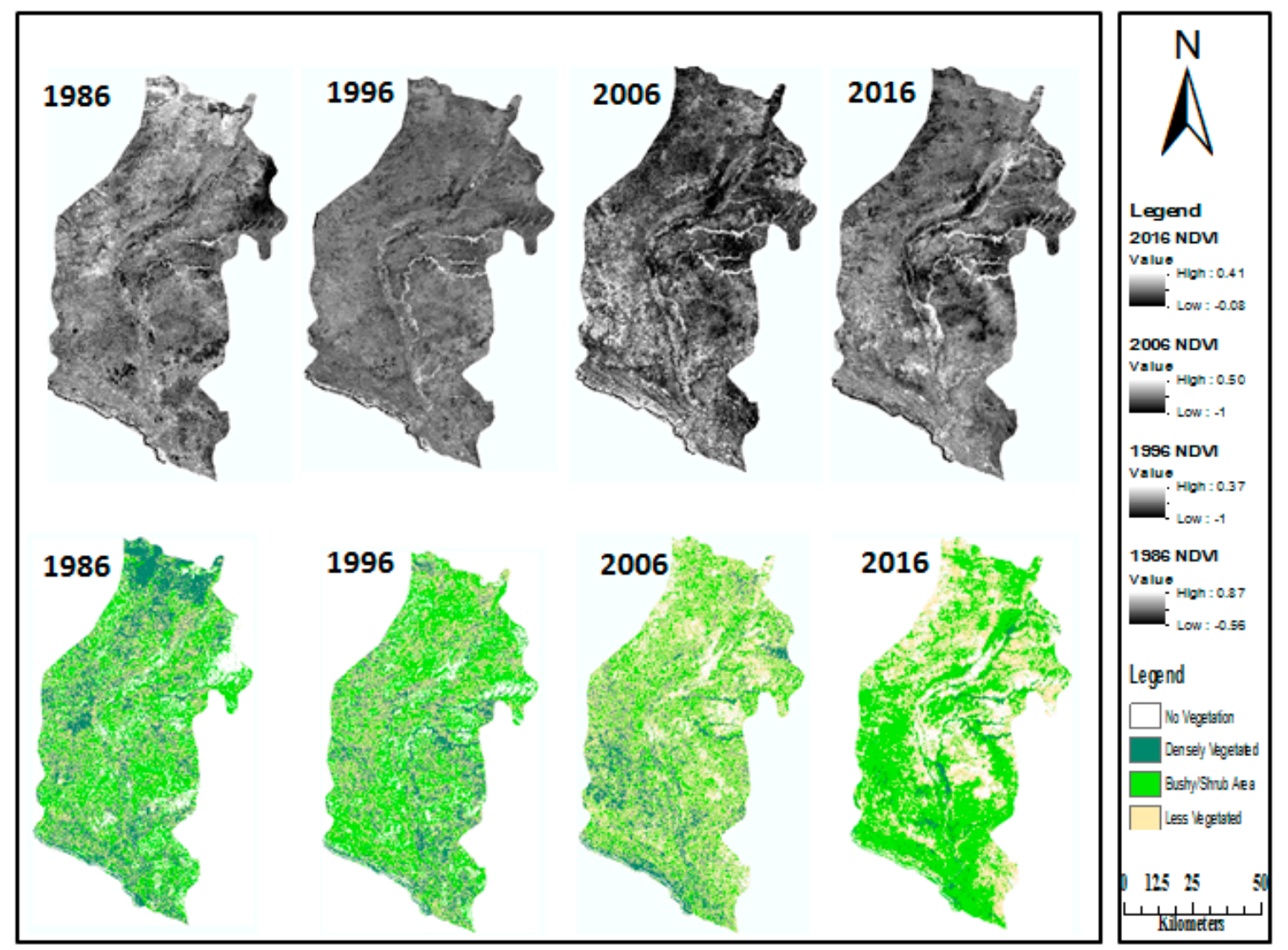

Fig. 6. Normalized Difference Vegetation Index Map (1986-2016)

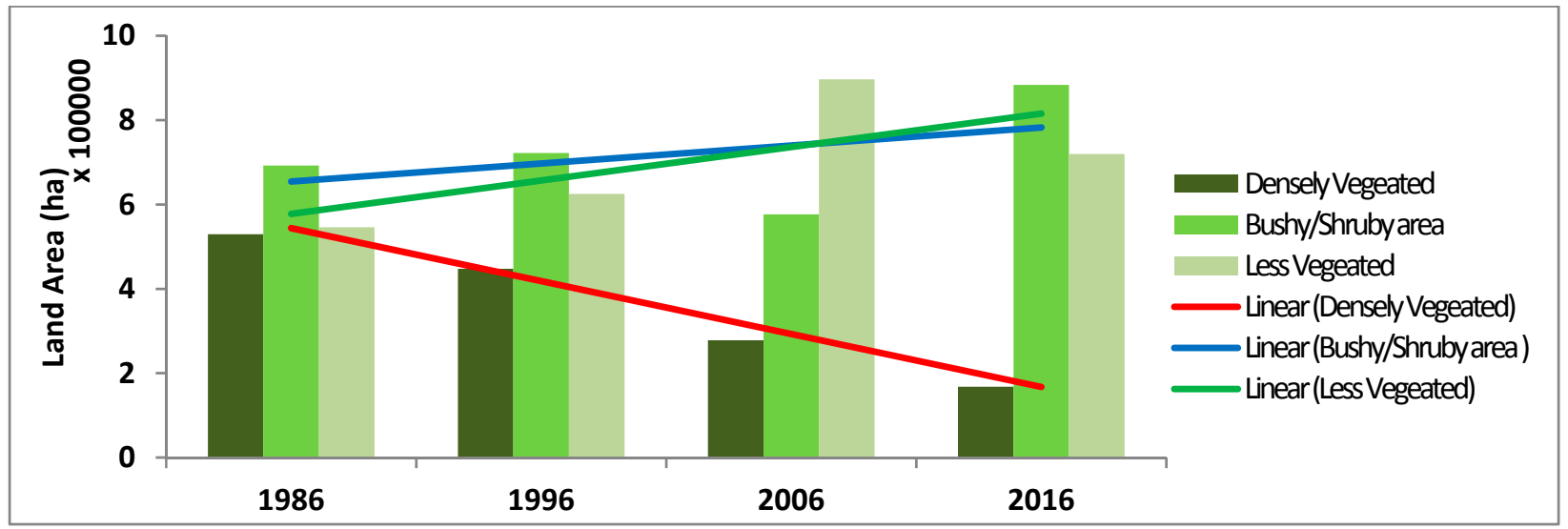

Fig. 7. Change in Vegetation Cover in the study area

\subsection{Accuracy assessment}

Classification accuracy assessment is the measure of the relationship between a reference data set and classified thematic map. It indicates a general agreement between ground truth data and a classified thematic map of an area under investigation. It is commonly a table of error matrix 
between the selected pixels as ground truth regions of such classes and the categorically classified map. For this study, the overall accuracy for both 1986, 1996, 2006 and 2016 is $72.72 \%, 71.88,78.23$ and $75.79 \%$ with Kappa coefficient $0.609,0.601,0.655$ and 0.635 respectively.
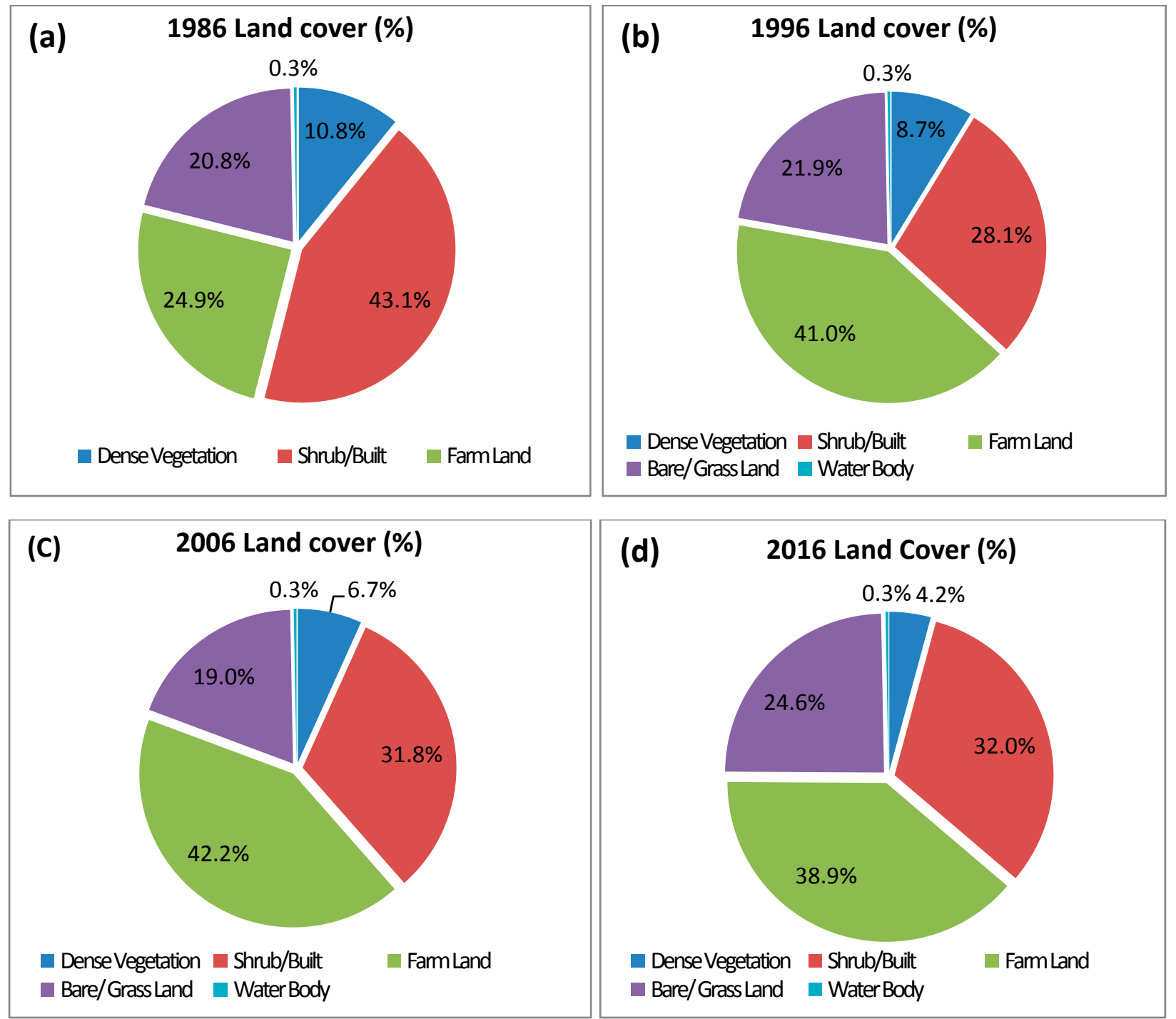

Fig. 8. Percentage Land cover change distribution (1986-2016)

\subsection{Analyses of Land cover change and Vegetation dynamics using DPSIR framework}

DPSIR framework as the nomenclature implies is a platform for the explanation of the driving force, pressure, state, impact and responses to a particular phenomenon in a particular environment. In the context of this study, the results of LCC and VD were examined using the 
components of DPSIR framework as it provides a linkage not only between the causes of the change and their impacts but also some of the remediation action in the environment.
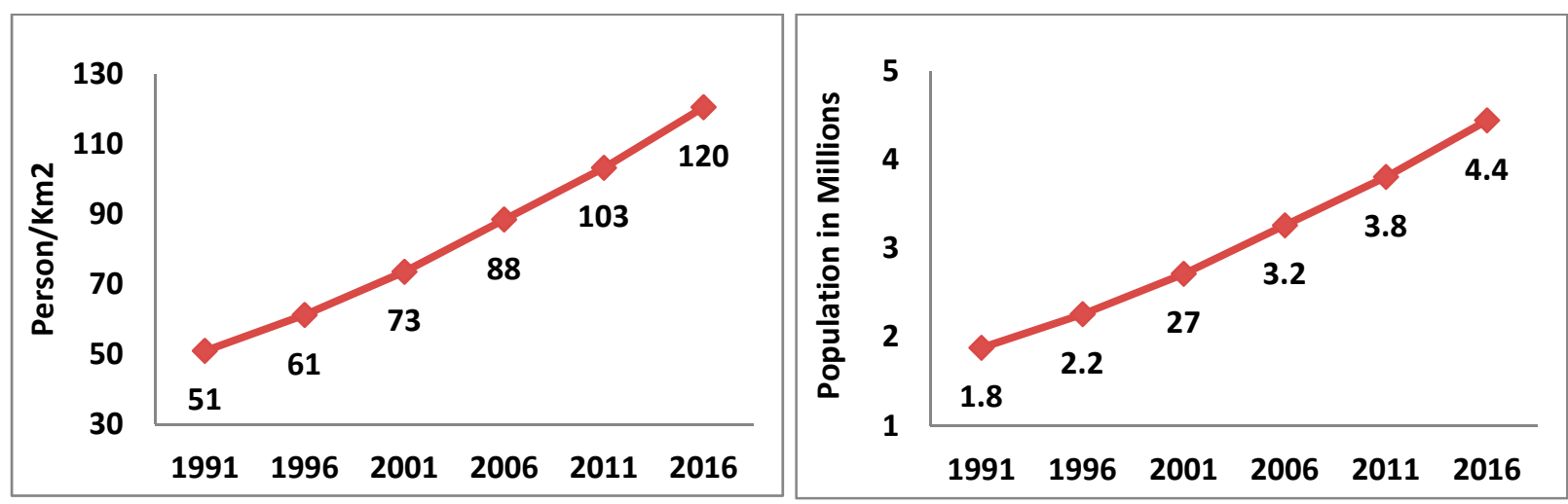

Fig. 9. (a) Population growth (b) Population Density of Kebbi State (Sources: National Population Commission of Nigeria)

\subsubsection{Drivers}

Drivers are emergent forces that generate socio-economic changes in order to meet the basic living needs. They may include the need for basic necessities of the livelihood of the community. These forces can be global, regional or local depending on the social setup of a community. The drivers encompass all human activities that exacerbate pressure on the environment. They may include population growth, socioeconomic demands, low level of income, livelihood needs such as food, shelter, means of energy etc. In view of the recurring LCC and VD in Kebbi state, population pressure, fuelwood consumption, poverty has compounded the problem. The increase in the population size is identified as the major key driver of environmental degradation. According to the population commission of Nigeria, the population size of Kebbi has been increasing rapidly from 1.8m-4.4m between 1991-2016.

Fig. 9 above shows the trend of population growth and a population density of the study area from 1991-2016. Another driver is fuelwood consumption, the survey carried out in the study area indicate that more than $84 \%$ of the populace relied on fuelwood as a means of energy for their domestic use (fig. 10a). This is in line with the data from the national bureau of statistics of Nigeria indicating the same but a beat higher pattern of fuelwood consumption of about $90 \%$. Low level of income which relates to poverty is another important driver, the report by the Human development of the United Nations development programme [19], indicates that Nigeria's multidimensional poverty index is about 0.28 , which puts Nigeria in the bottom of the 
list of low human development index of the world [19]. The same kind of report by the national human development of Nigeria indicates Kebbi state among the poor state in Nigeria with a multidimensional poverty index of about 0.315 [20].

There is a very high correlation between Poverty and natural resources dependency, which commonly creates competition for the provision of ecosystem goods and services, leading to the over-exploitation of the resources.

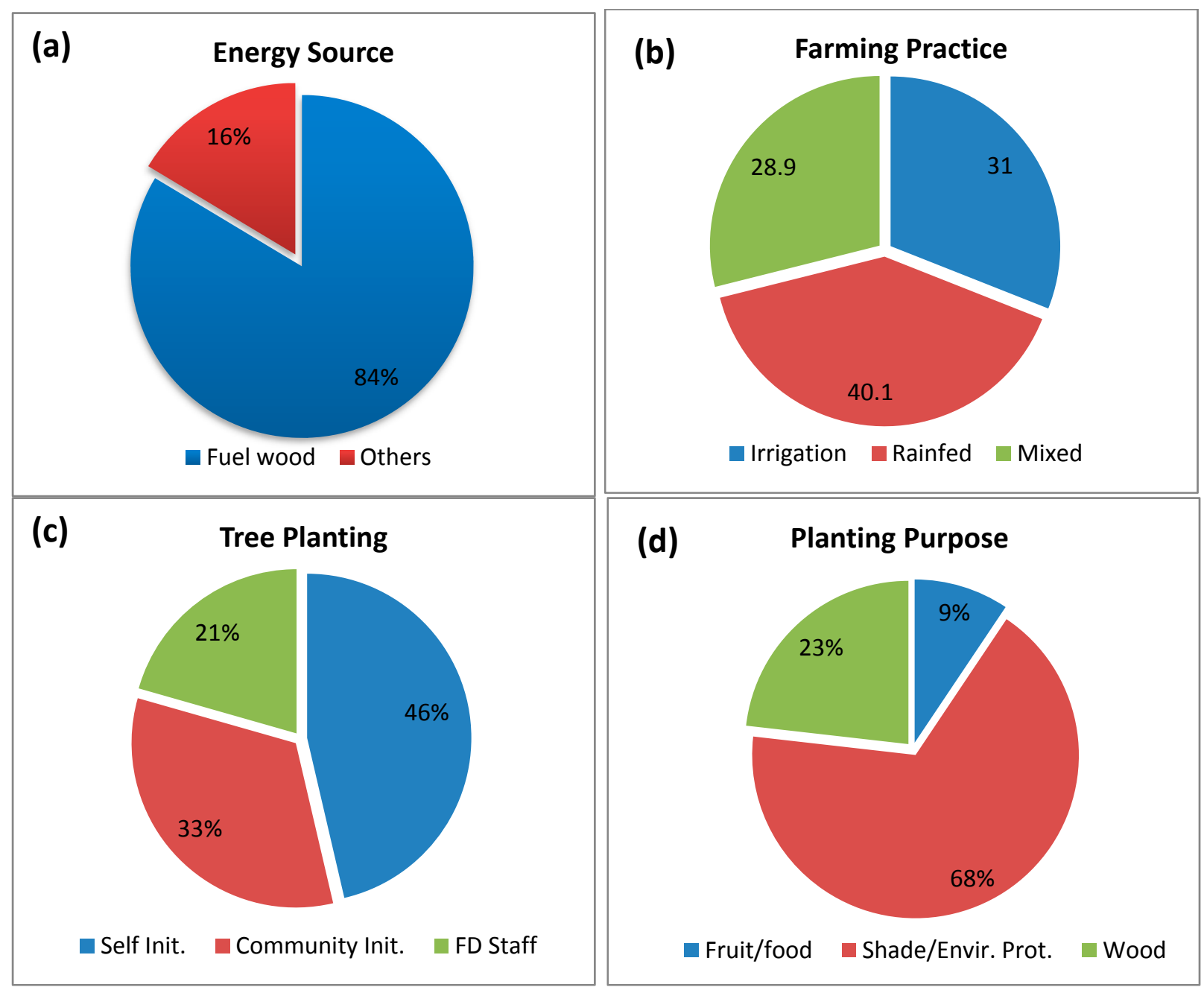

Fig. 10. (a) Sources of energy for domestic use (b) Farming Practice (c) Local Tree Planting Initiative (d) Planting purpose in Kebbi state (Source: Field Survey 2016)

\subsubsection{Pressures}

Pressures are mainly caused by driving forces on the environment, they relate to land use change, pollution and over-exploitation of natural resources, however, it varies depending on the scale and intensity of the socioeconomic demand. Increase in population facilitates the demand for farming land; however, drives to the cultivation of marginal land and biodiversity hotspots, such 
as forests, riverine area and hill slopes [11]. In the study area, the survey conducted indicate that, the form of agricultural practices are irrigated and rainfed as in with many of the populace practices subsistence farming through rain-fed agriculture (Fig. 10b) which requires more land; however, this practice ensures the clearing of forests and shrubs for farmlands, which led to the subsequent land cover conversion and vegetation deflation with adverse effect on habitat and biodiversity loss in the area. On the other hand irrigated farming requires less land but input intensive as it requires more chemical and water; this puts more pressure on water catchment area through deflation and pollution. The survey conducted also indicates that more than $70 \%$ of the population practice one form of Agriculture or another. This shows the lack of alternate means of income generation activities; this led to more pressure exerted on the natural resource for living sustenance.

\subsubsection{State}

State reveals the current situation or condition of the environment in terms of its potential to provide the necessary basic needs of the society. It tells the state of the condition of both biotic and abiotic constituents of a given environment. The state of an environment is commonly dictated depending on the pressures exercised upon it. In this study, three decades (3) analysis of RS data for both LCC (Fig. 4) and the NDVI (Fig. 6) were presented, indicating a steady decline in dense vegetation and shrubs area while Farmland and bare/grassland were increasing significantly. Likewise, during the field survey, many farmers have reported a decline in the farming output.

\subsubsection{Impacts}

Impacts relates to the changes in the environment that affect the well-being of the society such as the provision of goods and services that a particular society depends on. Currently, there is severe vegetation degradation, which has resulted in the biodiversity loss and land degradation especially in the northern part of the area. The availability of wild animals has declined as their habitats are damaged. The effect of land degradation is tremendous to the extent that, villages and their major access roads were buried by sand dunes in the extreme northern parts of Nigeria [21]; resulting in forced migration of affected human and livestock populations from these areas [22]. All these have posed a negative impact on livelihoods and well-being of the populace in the area.

\subsubsection{Responses}

Responses include the reactions to inherent changes in the environment. There are different levels of responses; it may range from high, at policy level down to local, society or even at the individual level for remediation of the impact imposed by the environment. Responses can be on 
the exerted pressures or may be an attempt to maintain the status quo or improving the current condition of the environment. In the study area, the main environmental issue is vegetation and land degradation causing a steady decline in the provision of good and services. As such many international and national policies in response to land degradation are channeled toward land restoration and remediating of the environment, through afforestation programmes $[23,24,25$, 26, 27] and improving the livelihood of the rural people [28], thereby providing alternative income sources [29, 30, 31], since they depend heavily on land for sustenance. At community and individual level, according to the field survey conducted, about $46 \%$ at individual and $33 \%$ at the community level (Fig. 10c), commonly organized annual tree planting campaign and $(67 \%)$ of these initiatives are mainly for the purpose of environmental protection (fig. 10d).

\subsection{Conclusion}

RS based CD techniques provide the baseline information on LCC and VD for three decades (1986-2016) in Kebbi state. Within this time frame, Dense Vegetation has declined rapidly by about $61 \%$ with its larger portion being converted to bare/grassland and farmland. It is clear that there is also a downturn in the shrubs Land by about $25.7 \%$. Bare/grassland has increased by about $18.2 \%$ in the area while Farmland increased by $35.9 \%$. Water bodies remain unchanged. The Integration of RS and the DPSIR framework provides a unique explanatory platform for better understanding of the drivers the impact and responses on the adverse LCC and VD in the area. Further studies need to be conducted on the future land cover predictions so as to furnish the decision makers with synaptic information on the future scenario LCC that are likely to occur. There is also need to integrate the soil and climatic variables for a better understanding of the phenomena. The limitation of this study lies in the use of low-resolution data set as such urgent need to apply a very high-resolution data for better result accuracy.

\section{Acknowledgments}

This research was funded by the tertiary education trust funds (TETFund) of Nigeria through Kebbi state university of Science and technology, Aliero. The authors wish to thank the anonymous referees for their valuable comments. The authors also acknowledge the USGS for providing the data freely available for project of this kind.

\section{Conflicts of Interest}

The authors declare no conflict of interest. 


\section{References}

1. Gann, G. D. \& Lamb, D. Ecological Restoration - a means of conserving biodiversity and sustaining livelihoods International and the IUCN Commission on Ecosystem Management.(2002).Availableonline:http://www.regionalconservation.org/ircs/pdf/publication /Gann\&Lamb(2006).pdf. (Accessed on 23 April, 2016)

2. Kumar, P., Rani, M., Pandey, P. C., Majumdar, a \& Nathawat, M. S. Monitoring of deforestation and forest degradation using remote sensing and GIS: A case study of Ranchi in Jharkhand (India). Rep. Opin. 2, 55-67 (2010).

3. Khaine, I. \& Woo, S. Y. An overview of interrelationship between climate change and forests. Forest Sci. Technol. 11, 11-18 (2014).

4. Virginia H. Dale, Linda a. Joyce, Steve Mcnulty, Ronald P. Neilson, Matthew P. Ayres, Michael D. Flannigan, Paul J. Hanson, Lloyd C. Irland, Ariel E. Lugo, Chris J. Peterson, Daniel Simberloff, Frederick J. Swanson, Brian J. Stocks, and B. M. W. Predicting species invasions using ecological niche modeling: new approaches from bioinformatics attack a pressing problem. Bioscience 51, 363-371 (2001).

5. Aguilar, F. J. et al. A quantitative assessment of forest cover change in the moulouya river watershed (Morocco) by the integration of a subpixel-based and object-based analysis of Landsat data. Forests 7, 1-19 (2016).

6. Lu, D., Mausel, P., Batistella, M. \& Moran, E. Land cover binary change detection methods for use in the moist tropical region of the Amazon: a comparative study. Int. J. Remote Sens. 26, 101-114 (2005).

7. Pang, C., Yu, H., He, J. \& Xu, J. Deforestation and changes in landscape patterns from 1979 to 2006 in Suan County, DPR Korea. Forests 4, 968-983 (2013).

8. Zhao, X., Xu, P., Zhou, T., Li, Q. \& Wu, D. Distribution and variation of forests in China from 2001 to 2011: A study based on remotely sensed data. Forests 4, 632-649 (2013).

9. John R. Jensen. Introduction to Digital Image Processing, A Remote Sensing Perspective. (Pearson Prentice Hall, 2005).

10. Singh, A. Review Article Digital change detection techniques using remotely-sensed data. Int. J. Remote Sens. 10, 989-1003 (1989).

11. Pullanikkatil, D., Palamuleni, L. \& Ruhiiga, T. Assessment of land use change in Likangala River catchment, Malawi: A remote sensing and DPSIR approach. Appl. Geogr. 71, 9-23 (2016).

12. Gari, S. R., Newton, A. \& Icely, J. D. A review of the application and evolution of the DPSIR framework with an emphasis on coastal social-ecological systems. Ocean Coast. Manag. 103, 63-77 (2015).

13. Quan, Y., Wang, C., Yan, Y., Wu, G. \& Zhang, H. Impact of inter-basin water transfer projects on regional ecological security from a telecoupling perspective. Sustain. 8, (2016). 
14. Haase, D. \& Nuissl, H. Does urban sprawl drive changes in the water balance and policy?. The case of Leipzig (Germany) 1870-2003. Landsc. Urban Plan. 80, 1-13 (2007).

15. Omann, I., Stocker, A. \& Jager, J. Climate change as a threat to biodiversity: An application of the DPSIR approach. Ecol. Econ. 69, 24-31 (2009).

16. Rahman, S., Faisal, B., Rahman, M. \& Taher, T. Analysis of VIA and EbA in a River Bank Erosion Prone Area of Bangladesh Applying DPSIR Framework. Climate 4, 52 (2016).

17. Sarmin, N. S., Mohd Hasmadi, I., Pakhriazad, H. Z. \& Khairil, W. A. The DPSIR framework for causes analysis of mangrove deforestation in Johor, Malaysia. Environ. Nanotechnology, Monit. Manag. 6, 214-218 (2016).

18. Patrício, J., Elliott, M., Mazik, K., Papadopoulou, K.-N. \& Smith, C. J. DPSIR-Two Decades of Trying to Develop a Unifying Framework for Marine Environmental Management? Front. Mar. Sci. 3, 1-14 (2016).

19. UNDP. Human Development Report 2016. (2016). Available online: http:/hdr.undp.org/en/countries/profiles/NGA. (Accessed on 14 May, 2017)

20. Federal Government of Nigeria. National Human Development Report. (2015). Availableonline:http://hdr.undp.org/sites/default/files/2016_national_human_development_re port_for_nigeria.pdf. (Accessed on 22 July, 2017)

21. Idris Medugu, N., Rafee Majid, M. \& Johar, F. Drought and desertification management in arid and semi-arid zones of Northern Nigeria. Manag. Environ. Qual. An Int. J. 22, 595-611 (2011).

22. Ayuba, N. M. G. H. K. On major environmental problems of desertification in northern Nigeria with sustainable effort to managing it. World J. Sci. Technol. Sustain. Dev. 13, (2016).

23. Mohammed Ibrahim, k. \& Inuwa Muhammad, s. A review of afforestation efforts in Nigeria. Int. J. Adv. Res. (2015).

24. FGN. Combating Desertification and Mitigating the Effects of Drought in Nigeria. (2005).

25. NAPCD. Federal Ministry of Environment: National Action Programme To Combat Desertification. (2005).

26. Idris Medugu, N., Rafee Majid, M., Johar, F. \& Choji, I. D. The role of afforestation programme in combating desertification in Nigeria. Int. J. Clim. Chang. Strategy. Manag. 2, 35-47 (2010).

27. Olagunju, T. E. Drought, Desertification and the Nigerian Environment: A review. J. Ecol. Nat. Environ. 7, 256-262 (2015).

28. IFAD: IOE. Federal Republic of Nigeria: Country Programme Evaluation. (2016). Available online: https://www.ifad.org/documents/10180/f68ffd73-b97e-47ab-b3a3-c8b364facc8c (Accessed on 23 June, 2017) 
29. Shuaibu, R. B. Women's involvement in forestry practices as livelihood options in igalamela /odolu local government area, Kogi state, Nigeria. J. Res. For. Wildl. environment 1, 13-22 (2015).

30. Kunle, K. \& Abubakar, N. M. Assessment of the ifad-cbardp activities towards poverty alleviation in kebbi state, Nigeria 1. Int. J. Adv. Res. Public Policy, Soc. Dev. Enterp. Stud. 2, 47-58 (2017).

31. A. I. Illo, A. K. Ango, H. U. \& Z. A. Role of International Fund for Agricultural Development-Community Based Agricultural and Rural Development Programme (IFADCBARDP) in Improving the Livelihood of Rural Women: A Case Study of Aliero Local Government Area, Kebbi State, Nigeria. Niger. J. Basic Appl. Sci. 23, 23-30 (2015). 